\title{
Correção politicamente carregada
}

SCABIN, N. L. C.

Politicamente correto,

Ivan Paganotti'

I - FIAM/FAAM

São Paulo (SP), Brasil

uma categoria em disputa.

Curitiba: Appris, 2018, 194 p.

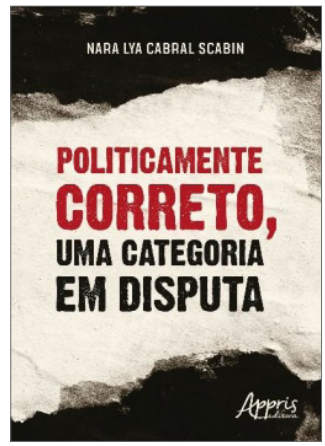

Resumo: O livro resenhado analisa as origens e transformações dos discursos ao redor do termo "politicamente correto". Com base na análise de 149 reportagens e artigos de opinião publicados pelo diário Folha de S. Paulo desde 1990, o livro reconstrói cronologicamente três momentos diversos: uma primeira apresentação desse termo importado da cultura norteamericana como uma "tendência" de comportamento individual; um "movimento" cultural da esquerda, com objetivos políticos para combater a discriminação por meio da troca de palavras ofensivas; uma "ideologia" de um grupo que passa a conquistar estruturas de poder e que pode ameaçar a liberdade de expressão. A obra avalia a relação entre a postura predominantemente crítica da cobertura da Folha sobre o politicamente correto e o surgimento de um influente discurso no campo político oposto, que defende o politicamente incorreto.

Palavras-chave: politicamente correto; Folha de S. Paulo; análise de discurso.

Abstract: Politically charged correction - This book analyzes the origins and transformations of discourses around the term "politically correctness". The book evaluates 149 articles and opinion articles published by Folha de S. Paulo since 1990, chronologically reconstructing three different moments: at first, this term is imported from American culture as a "trend," or an individual behavior; then, it is represented as a cultural "movement" from the left, with political objectives to combat discrimination through the replacement of offensive words; finally, as an "ideology" adopted by a group that conquers power structures that could threaten free speech. The book assesses the relationship between the Folha newspaper' predominantly critical position against politically correct practices, and the emergence of an influential discourse in the opposite political field, which supports politically incorrectness.

Keywords: political correctness, Folha de S. Paulo, discourse analysis. 
Líderes políticos têm conquistado apoio popular adotando uma estratégia que seria suicida poucos anos atrás: usando uma linguagem flagrantemente ofensiva, parecem não se preocupar com sensibilidades alheias, atropelando limites esperados por minorias e grupos que se sentem ofendidos com representações que aparentavam estar reservadas para os museus da vergonha. Pelo contrário, parece que buscam justamente apresentar-se como indivíduos sem papas nas línguas, dispostos a jogar contra as convenções de moderação da linguagem. Se essa conduta resultaria em infâmia e ostracismo no passado recente, parece que parcela considerável do público passou a tolerar e até sustentar discursos mais hostis e até ofensivos. Nos EUA, na França, nas Filipinas e também no Brasil, líderes políticos ganham projeção e se aproximam - ou até conquistam - cargos determinantes para as escolhas políticas da coletividade. Ao mesmo tempo, esses representantes eleitos sugerem novos limites flexíveis de moderação e indicam o retorno de comportamentos que pareciam não ser mais considerados aceitáveis para a sociedade.

Esse fenômeno político foi precedido pela retomada, na década anterior, de discursos vistos como potencialmente explosivos como um mecanismo de promoção e destaque entre artistas na esfera cultural - particularmente entre comediantes. Reconstruir o nascimento e a evolução desse fenômeno linguístico e seus usos políticos é essencial para refletir e potencialmente intervir sobre essa mudança dos parâmetros discursivos passíveis de sanção ou aplauso na esfera pública.

Vem em boa hora, portanto, a publicação do livro "Politicamente correto, uma categoria em disputa", de Nara Lya Cabral Scabin (2018). A autora atualiza e dá formato mais acessível para sua pesquisa de mestrado na USP sobre as origens, transformações e críticas do discurso que é caracterizado como "politicamente correto" - ou PC. Até mesmo a definição do que seria PC é bastante polêmica, visto que o termo foi cunhado originalmente por seus detratores e abarca práticas e estratégias bastante diferentes (SCABIN, 2018, p. 151). Entretanto, Scabin alinha elementos em comum entre as definições de linguistas e cientistas políticos como Sírio Possenti, Renato Janine Ribeiro e Norman Fairclough, e aponta que o PC pode ser visto como um mecanismo de

[...] classificação de diferentes formas de representação (dentre as quais, a linguagem verbal) como 'corretas' ou 'incorretas', prescrevendo o uso das primeiras e condenando o uso das segundas, com o objetivo de combater preconceitos e discriminações, a fim de se produzir mudança social (SCABIN, 2018, p. 34).

Destaca-se, em primeiro lugar, que o PC pode ser visto como uma estratégia política para intervir sobre a discriminação por meio da representação simbólica. É um processo invocado por minorias discriminadas - ou grupos que tentem falar em seu lugar, como seus representantes - como forma de disputa no espaço público, marcando os termos que serão considerados como aceitos ou não no problemático ato de nomear o outro (SCABIN, 2018, p. 41), lutando para que prevaleçam novos termos, substituindo outros 
vistos como arcaicos ou incômodos. Essa expressão também pode referir-se ao resultado dessa ação política, já que um discurso será considerado politicamente correto se seguir essa classificação, evitando certos termos e adotando seus novos substitutos.

A autora analisa a recepção brasileira dessa expressão originária da cultura política norte-americana por meio da análise das representações sobre o termo "politicamente correto" nas páginas do jornal diário Folha de S.Paulo, veículo pioneiro na difusão e na crítica do PC no país. Usando uma metodologia inspirada nos processos de arqueologia de Foucault (2008), Scabin (2018, p. 73) busca entre os arquivos digitais do diário paulistano as 149 reportagens e artigos opinativos que tratam de apresentar, defender ou criticar o PC desde o início dos anos 1990. Nessas quase três décadas, esse termo passou por processos de transmutação: de uma tendência cultural adotada por um público preocupado e progressista, o PC passou a ser visto como um movimento identitário oriundo da esquerda e com objetivos políticos, até ser criticado como uma ideologia doutrinária e moralista que poderia ameaçar a liberdade de expressão (SCABIN, 2018, p. 100).

Além dessa didática periodização, vale destacar a instigante ausência, identificada por Scabin (2018, p. 123), de "agentes ou instituições responsáveis pelas propostas e iniciativas" identificadas como PC em grande parte dos textos publicados pela Folha. É bastante revelador que grupos que advogam suas próprias formas de identificação para combater a discriminação acabem sendo representados genericamente, de forma indiscriminada, e por um termo cunhado por outros. Da mesma forma, "são também raras as ocasiões em que o jornal concede voz a representantes de movimentos e minorias sociais e cede espaço aos argumentos apresentados por esses setores" (SCABIN, 2018, p. 130). Por outro lado, essa ausência pode ser devida aos critérios de recorte e seleção dos textos analisados neste livro: como a autora avalia os artigos que trazem o termo "politicamente correto", muitas vezes usado por críticos dessas práticas e evitado por seus defensores, talvez o jornal possa ter dado espaço para esses movimentos, mas em textos que acabaram fora do corpus deste estudo e possam vir a ser analisados futuramente.

Também é digna de nota a moderada contradição apontada por Scabin $(2018,140)$ entre a frequente crítica ao politicamente correto nas páginas da Folha e reportagens de 1992 sobre o manual de redação desse mesmo diário, que continha lista de palavras que "devem ser evitadas - por serem pejorativas -, quais são desejáveis - por serem supostamente 'neutras' - e quais não são recomendáveis por exagerarem no grau de correção - ou seja, por serem 'politicamente corretas' demais". Como destacado pela autora, muitos dos termos que deveriam ser evitados pela Folha em 1992 voltariam a aparecer na famigerada cartilha Politicamente Correto \& Direitos Humanos, editada pelo Governo Federal treze anos depois e alvo de "críticas contundentes" (SCABIN, 2018, p. 141) nas páginas desse mesmo periódico.

Por fim, Sabin (2018, p. 156) destaca que a crítica ao PC acabou por criar em seu contracampo um discurso "politicamente incorreto". O que se iniciou como uma crítica 
às limitações da substituição de termos ofensivos como forma de combate à discriminação, passou a ser uma marca do campo ideológico oposto ao dos movimentos de onde surgia a preocupação com termos ofensivos, galvanizando um público que mistura a defesa da liberdade de expressão com um mecanismo de mobilização política à direita. A popularidade desse fenômeno liberal-conservador se torna evidente no sucesso de artistas e humoristas, e estampa o sucesso editorial de uma série de livros que trazem o "politicamente incorreto" em seu título (SCABIN, 2018, p. 160). Com isso, Scabin identifica no final dos anos 2000 o surgimento dos discursos politicamente incorretos que recusam os novos termos defendidos pelos movimentos sociais, reforçando representações flagrantemente ofensivas como um mecanismo de projeção por meio dessa mesma polêmica: como apontado por Scabin (2018, p. 172), o politicamente incorreto passa a ser visto por muitos como um "selo de qualidade" para produções culturais provocadoras.

O estudo de Scabin é valioso para entender como os termos "adequados" ou "inadequados" passaram por essa surpreendente ressiginificação: a resistência à classificação do PC inverteu os polos, pois trouxe hostilidade para grupos periféricos que pretendiam sugerir uma representação de suas identidades de forma menos ofensiva, e atraiu a atenção para práticas de nomeação (adotadas por grupos tradicionais) que se pretendia condenar. A tragédia do politicamente correto parece ter transformado sua defesa em prática marginal, dando uma sobrevida para discursos problemáticos, inadvertidamente apresentando um palco para que representantes de pensamentos arcaicos se reposicionem como novos defensores da liberdade de expressão.

Ivan Paganotti é professor do Mestrado Profissional em Jornalismo do FIAM-FAAM Centro Universitário e doutor em Ciências da Comunicação pela ECA-USP, com estágio doutoral na Universidade do Minho (Braga/Portugal, Capes).

ivan.paganotti@fiamfaam.br

\section{Referências}

FOUCAULT, M. A arqueologia do saber. Rio de Janeiro: Forense Universitária, 2008.

SCABIN, N. L. C. Politicamente correto, uma categoria em disputa. Curitiba: Appris, 2018. 